\title{
A Review on Mobility and Mobility Aware MAC Protocols in Wireless Sensor Network
}

\author{
Ankur V. Gondha \\ Student (M.Tech. - E\&C) \\ Electronics and Communication Engineering \\ Department \\ School of Engineering \\ RK University \\ Rajkot, India.
}

\author{
Arjav A. Bavarva \\ Assistant Professor \\ Department of Electronics and Communication \\ Engineering \\ School of Engineering \\ RK University \\ Rajkot, India. \\ arjav.bavarva@rku.ac.in
}

\begin{abstract}
Wireless Sensor Networks are usually limited with storage capacity, power consumption, computing power and mobility detection. But now a day wireless sensor networks facing a major problem of detection of mobile sensor nodes while doing a periodic detection or continuous monitoring of an event. So, this paper gives a review about different mobility patterns and comparison of Mobility Aware MAC protocols, which helps one for the better selection of MAC protocol in different mobile wireless sensor network applications. This review is the initial part of the research for developing the algorithm to extend the results, which are already achieved in the previous research.
\end{abstract}

\section{General Terms}

Mobility Aware Mac Protocols, Wireless Sensor Network.

\section{Keywords}

MAC Protocol, Mobility, Sensor Node, WSN- Wireless Sensor Network, TDMA, Data Packets, Mobility.

\section{INTRODUCTION}

The wireless sensor network is infrastructure less network that consist of small sensors nodes scattered in the sensing environment and one or more sink node(s).Sensors are used to collect environmental data (like temperature, humidity, etc.) and send them to the sink. Nodes are embedded with a microprocessor and a wireless transceiver along with the sensory unit providing data processing and communication capabilities in addition to the sensing facility. Wireless Sensor Network can be helpful in applications like in Military, Environment control and Biodiversity mapping, Medicine and Healthcare [6]. In such application network should be able to allow nodes to move freely and should relate nodes come across. Such type of networks requires continues dynamic reconfiguration to maintain the efficient communication between existing nodes in wireless sensor networks.

Without considering mobility of sensor nodes, delay is produced due to gradual degradation in link quality and ultimately link break down occurs [2]. To maintain efficient communication in presence of mobility of nodes on either side in wireless sensor network efficient Mobility Aware MAC protocols like MS-MAC, M-MAC, M_TDMA, MA-MAC, MCMAC, MobiSense, etc are required. This detects the mobility of nodes on either side of the transmission and changeover of the link without breakage of previous link / dynamic data rate adaption to avoid retransmission. Ultimately efficient data transmission takes place.

\section{MAC PROTOCOLS IN WSN}

$\mathrm{MAC}$ is the second layer after the physical layer in the OSI model in networking systems. MAC protocols controls when to send and receive distinguished packet between nodes in a network. It controls the network interface when to establish the connection or the transaction between two or more nodes.

Manipulating the operation of a MAC protocol can give its effect in terms of energy. All MAC protocols for wireless networks manage the usage of the radio interface to ensure efficient utilization of the shared bandwidth. MAC protocols designed for wireless sensor networks have an additional goal of managing radio activity to conserve energy. Thus, while traditional MAC protocols must balance throughput, delay, and fairness concerns.MAC layer affects the energy efficiency mainly through the adjustment of transmission scheduling and channel access. A common way to do that is via sleep scheduling from a long time scale, or time-division multiple accesses (TDMA), from a short time scale perspective. Similar to the shutdown technique of CPUs, sleep scheduling also explores the energy vs. response time tradeoffs in wireless communication. According to a survey on Wireless Sensor Networks, major sources of energy waste at medium access communication are a) collision - which requires retransmission of collided packets, b) overhearing - where a node receives a message meant for another node, c) control packet overhead - where energy is consumed in exchange of control packets used for control data transmission and d) idle listening - which means that node is listening to idle channel and then over-emitting by sending packets when the destination node is not yet ready [6].

Among all reasons mentioned above idle listening is a major cause of energy waste [6]. So, it is important to design a suitable MAC protocol which can reduce above energy wastes. There are four techniques to avoid idle listening static sleep scheduling, dynamic sleep scheduling, preamble sampling, and off-line scheduling. Based on these techniques, many MAC protocols based on CSMA, TDMA, hybrid and cross-layer optimizations were introduced. Another major source of energy wastage to be considered in MAC protocols is mobility of nodes in application like, Forest Fire detection and Investigation that has been done through mobile sensor nodes attached with wild animals or birds or reptiles. So, such mobility results in frequent topology change which results degradation in established link quality and prone to failure and increases the packet retransmission. Due to mobility of nodes, introduces frequent route change and produces delay in packet 
delivery on either side. To overcome these problems mobility aware MAC protocols are introduced.

\section{MOBILITY IN WSN AND MOBILITY PATTERNS}

In the mobile environment, wireless sensor network should be efficient enough to detect the mobility of sensor nodes or sink nodes to avoid the energy wastage. On the basis of that mobility can be classified in two types I) Node mobility and II) Sink mobility and III) Event mobility.

Sink is a node in wireless sensor network, which is final destination to collect the sensed data from the surrounding environment by sensor nodes. If sink node is mobile in the environment it is not easy to collect the whole sensed data by the sensor node. Mobility of sink node made requirement of efficient routing of sensed data otherwise it creates the delay or degradation or data loss in data transmission from sensor node (transmitter) to the sink node (receiver).

In case of node mobility sensor nodes are mobile in the network compared to static sink nodes. This improves the coverage area of the wireless sensor network but also facing delay or degradation or data loss in the data transmission. Which may be behaving as source node sensing data or may be behaving as a relay node just participate in the data transmission process without doing any process on the incoming data packets.

For mobility estimation in the wireless sensor network knowledge of mobility patterns should require. Mobility pattern is a movement of the real life subjects. And can be considered as a realistic mobility pattern. Realistic mobility patterns can be classified as pedestrians, vehicles, aerial, dynamic medium, robot, and outer space motion [14].

\subsection{Pedestrian Mobility Pattern}

Pedestrian mobility describes the walking patterns of people or animals. Main characteristics are the full use of the twodimensional plane with occasional obstacles and its nature. Group behaviour may occur, but has not necessarily to be. Such pedestrian mobility is always limited in speed. Typical examples of pedestrian mobility in wireless networks are people in the street or mall using cellular phones or PDAs (personal digital assistants), and animals or birds in herds with sensor nodes being observed by biologists.

\subsection{Vehicular Mobility Pattern}

It describes the movement of vehicles which are equipped with sensor nodes. Vehicles can communicate with each other conveniently by capturing traffic conditions and other information. In vehicle, wheel based movement reduces friction and allows high speed. So, the danger of collision increases dramatically, and this is the reason why all vehicles are bound to one-dimensional movement on streets, paths, or tracks. This reduces the problem of preventing collisions to certain places like crossings. Vehicle movement is one dimensional and characterizes group behaviour at a highspeed [14].

\subsection{Aerial Mobility Pattern}

Consider flying objects at high speeds and travel over long distances. Actually birds and airplanes behave quite similarly. As a communication medium open air is nearly optimal. Still, the signal fades with the distance, such that multihop communications may reduce the energy consumption of the radio transceiver. The aerial mobility pattern can be best described as a two and a half dimensional individual movement with limited (yet high) speed. The motion is not completely three-dimensional.

\subsection{Dynamic Medium Mobility Pattern}

To understand the mobility of the sensor devices in the medium one has to study the medium itself. Medium based mobility can be one-, two- or three-dimensional depending on the medium and the circumstances (piped gas, surface of fluids, open air). Group behaviour can occur and is usually unwanted since grouped sensors deliver less information than individual moving sensors. A typical example is to explore the interior of the hurricanes.

\subsection{Robotic Mobility Pattern}

Any of the above mobility scenarios can occur in robot motion. The main difference is the mobility pattern given by the designer of the robots. For some application this pattern is easy to predict, likewise other robots seem to move completely temperamental and unpredictable.

\subsection{Outer Space Motion Mobility Pattern}

For radio communication outer space is the perfect environment. Energy for communication is usually no tight resource since space vehicles are equipped with solar paddles. Mobility is, however, restricted since common space ships use rockets for acceleration and fuel supply is limited. Hence, space vehicles drift through space most of the time to save on this resource. Space explorations may produce even more complicated mobility patterns.

\section{CLASSIFICATION OF MAC PROTOCOLS IN WSN}

The MAC protocols in wireless sensor network can be broadly classified as, a) Contention Based, b) Schedule Based [6].

Schedule based protocol can avoid collisions, overhearing and idle listening by schedule transmission \& listen periods but requires strict time synchronization between nodes in the wireless sensor network. Proposed Schedule based (TDMA) protocols are LEACH, TRAMA, ERMAC, TRAMA, EMACS, DEMAC, BMA, SS-TDMA, LMAC, etc. While contention based protocols don't require strict time synchronization and can easily adjust to the topology changes as new nodes may join and active nodes may die after deployment. These protocols are based on Carrier Sense Multiple Access (CSMA) technique. The contention based (CSMA) have low latency and high throughput. However, it still suffers from the collisions. Proposed Contention based protocols are SMAC, TMAC, PCSMAC, BAMC, Wise MAC, DMAC, UMAC, XMAC, PAMC, CMAC, etc.

Some of the networks may experience a change in topology due to some reasons, for example, when new nodes join the network and when existing nodes experience hardware failure or exhaust their batteries (and, therefore, become inaccessible to their neighbours). This type of change in the topology of the network occurs seldom and is described in the literature as a change in the topology due to a weak mobility. Almost all of the MAC protocols in wireless sensor networks are able to deal with a slow change in a network's topology. For example, in SMAC [6] and TMAC [6], nodes update their knowledge about their neighbours by exchanging synchronization packets. Preamble-based protocols such as XMAC [12] and Wise MAC [13] avoid the need for periodic synchronization by sending a burst of preambles. However, all of these protocols enable nodes to perceive a change in their surrounding only at the beginning of each active period. Consequently, there is a delay in packet transmission 
whenever a topology change has occurred and the delay can be high in multi-hop networks. Since weak mobility takes place infrequently. So, simple MAC protocols (Contention based/Schedule based) can detect weak/slow mobility but can't handle the fast mobility patterns of mobile nodes in wireless sensor network.

On the basis of mobility of nodes in wireless sensor network MAC protocols can also be classified as Mobility Aware MAC protocols. Proposed Mobility Aware MAC protocols are MS-MAC, M-MAC, M_TDMA, MA-MAC, MCMAC, MobiSense, etc. Proposed Mobility Aware MAC protocols are either contention based or schedule based.

\section{ATTRIBUTS CONSIDERATION FOR MAC PROTOCOL IN WIRELESS SENSOR NETWORK HAVING DYNAMIC/MOBILE ENVIRONMENT}

Now a day for application like Fire fighting and Fire investigation faces mobility of sensor nodes in the wireless sensor network, requires efficient MAC protocol to avoid collision. For selection of good mobility aware MAC protocols following attributes have to be considered.

\subsection{Mobility}

The mobility problems in wireless sensor network also exist if the sensor nodes are mobile in given application. Due to mobility of sensor node on either side of data transmission degradation of link and ultimately link breakage occurs in case of wrong selection of MAC protocol.

\subsection{Delay}

When any event is detected by sensor node which is mobile in wireless sensor network it has to be reached in time to the sink node in time otherwise it is not considered as useful information. So, such lack of time in event detection application which is mobile is called delay. Delay can also be affected by mobility of sensor nodes.

\subsection{Throughput of Network}

It is a measure of total number of packets arrived at sink per time unit. Mobility of Sensor nodes also affect the network throughput because of packet loss due to link degradation between transmitting node and the receiving node or sink node. It can be increased by selection of mobility aware MAC protocol.

\subsection{Average Latency}

It is measure of average time taken by data packets to reach to the sink or receiving node. Mobility of sensor nodes also affects the average latency due to degradation of link quality in case of wrong selection of MAC protocol.

\subsection{Power consumption}

It increases due to retransmission of packets. Retransmission of packets is observed when degradation of link and ultimately link breakage in case of the wrong selection of MAC protocol in application facing mobility of sensor nodes.

\subsection{Energy Efficiency}

It decreases due to more power consumption in retransmission of packets in case of link breakage in terms of mobility of sensor nodes. It can be improved by the selection of the proper MAC protocols can detect the mobility and establish new multihop link before previous link degradation.

\section{MOBILITY AWARE MAC PROTOCOLS IN WSN}

In this section suggested mobility aware MAC protocols are briefly described to detect and overcome the mobility of nodes. Mobility of node creates the degradation in active data transmission link between nodes. When degradation in link quality is detected then following schemes can be proffered to avoid the inefficient data transmission [15].

I. Transmitting node can continue with active data transmission, if it is aware that it completes the task before the breakage of the transmission link [15].

II. Sensor nodes on both sides can adjust the high data rate in continuous data transmission to complete the task before the link breakage [15].

III. The seamless handover (hand-off) can be done with the continuous data transmission to prefer the better link [15].

For above decision requires the link layer to interact with the remaining layer for adjustment to support dynamic data rate, dynamic power consumption, dynamic range and packet size.

Suggested mobility aware MAC protocols can be suitable f or the different/same mobile environment to detect and the mobility and serve the efficient data transmission over link degradation.

\subsection{MA-MAC}

The mobility-aware medium access control protocol (MA$\mathrm{MAC}$ ) is an extended version of XMAC protocol. It is a transmitter initiated MAC protocol [2]. Just like all low duty cycle MAC protocols, MA-MAC protocol allows a node to sleep most of the time and switch on the radio for transmission and reception the packets periodically. In the static (immobile) environment, MA-MAC performs like XMAC by dividing a preamble into multiple strobes as awake up call and by enabling an early ACK packet to save energy Whenever mobility is detected by MA-MAC protocol it initiates a seamless handover to a new relay node before the link breaks, For detection of mobility of node RSSI can be measured of the acknowledgement packet by measuring the degradation of the link quality. For that two RSSI thresholds are considered. The first threshold motivates it to starts the handover while second threshold sets the upper limit of the handover process. Means before reaching to the second threshold level handover process must be completed otherwise link will be aborted.MA-MAC broadcast the handover request to the neighboring node. These requests are embedded with the data packets of the ongoing transmission. After selection of relay node for the handover process MA-MAC starts unicast in place of broadcast.

Figure 1 show a handover process in which a mobile sender (S1) evaluates the RSSI values of incoming ACK packets from a receiver $(\mathrm{R} 1)$. If the distance of separation between the two of them exceeds the first threshold, it begins to embed handover requests in the outgoing data packets and transmits them in a broadcast mode to the nodes R2 and R3. Thus it will send ACK packets for a short interval, to enable $S 1$ to collect handover replies from its surrounding. In case of no answer, S1 resumes communicating with R1 while keeping sending handover requests. Once R2 and R3 wake up and hear the neighbor discovery messages, they will send back handover replies. S1 will select the node from which it receives the first reply as a relay node (R2) and communicates with it. Meanwhile R3, by overhearing the data packet from S1, 
realizes that it has not been selected and thus goes back to sleep to save energy.

\subsection{M-MAC}

The mobility-adaptive, collision-free medium access control protocol (MMAC) is an extension of schedule based protocol TRAMA [11]. TRAMA is a distributed TDMA based MAC protocol. In it size of the frame as well as slot distribution takes place dynamically. The protocol divides the time frame in to two parts: a random access period and schedule access period. Schedule access period is to collect neighbor information while schedule access period announces the schedule of the transmission and performs the transmission. Instead of the fixed frame length in TRAMA, M-MAC introduces a flexible frame time that enables the protocol to dynamically adapt to mobility, making it suitable for mobile wireless sensor environments. In static environment M-MAC behaves like TRAMA protocol.

MMAC having a mobility-adaptive frame time that enables the protocol to dynamically adapt to changes in mobility patterns. M-MAC is suitable for mobile environments with both strong (concurrent node joins/failures and physical mobility of nodes) and weak mobility (topology changes, node joins, and node failures).MMAC assumes that the sensor nodes are aware of their location. This location information is used to predict the mobility pattern of the nodes according to the AR-1 model.

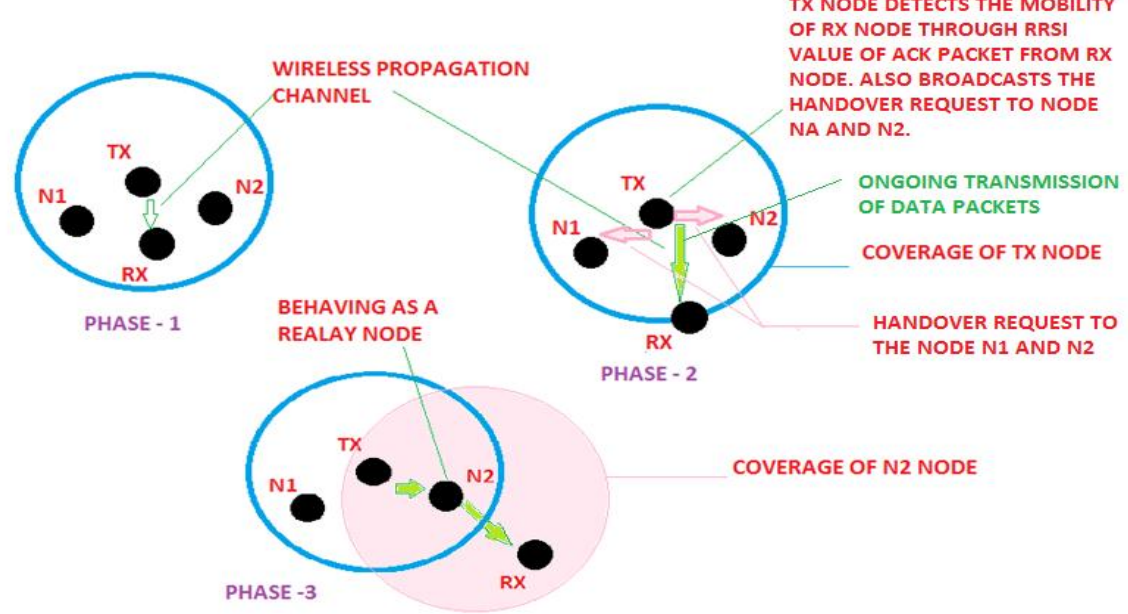

Fig 1: Working Scenario of MA-MAC protocol

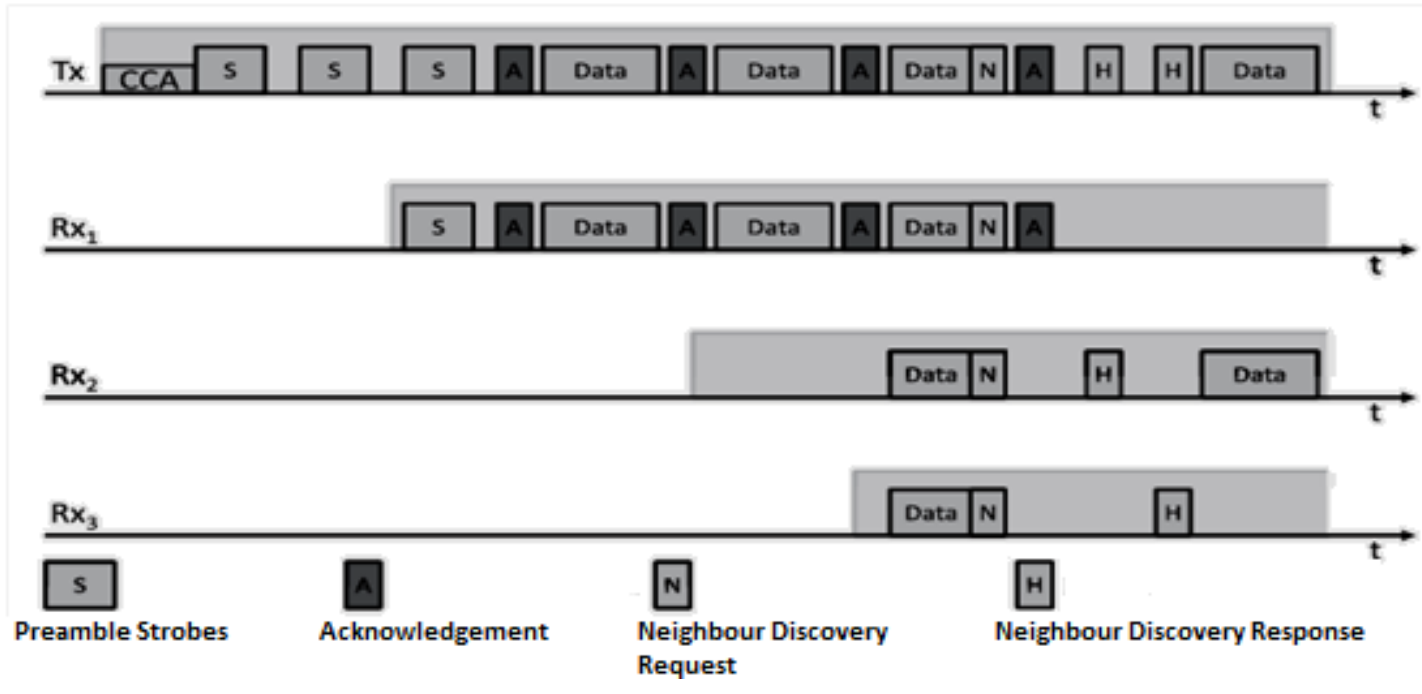

Fig 2: Data transmission and Handover Frame structure in MA-MAC Protocol [2] 


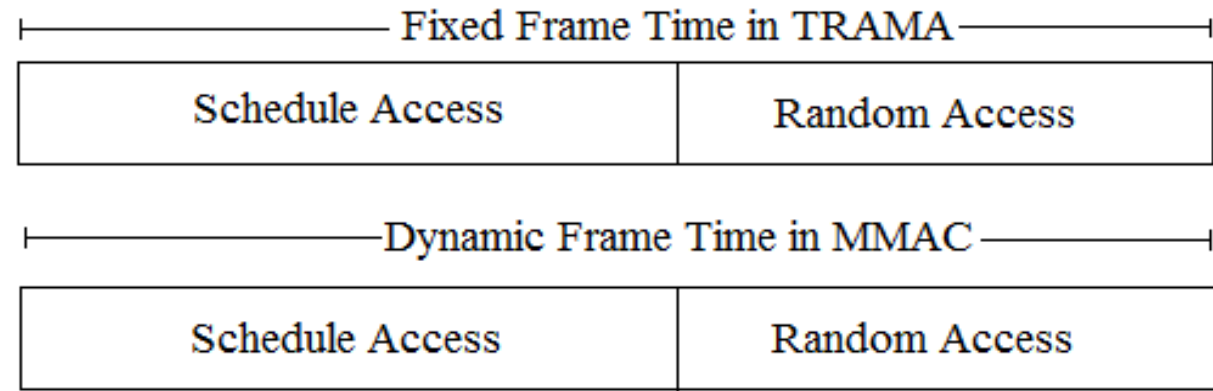

\section{$\longmapsto$ After Mobility Detection Frame Time in MMAC $\longrightarrow$}

\begin{tabular}{|l|l|}
\hline Schedule Access & Random Access \\
\hline
\end{tabular}

Fig 3: Dynamic frame structure of M-MAC Protocol [11]

\begin{abstract}
At the beginning of each frame, all the nodes in the network predict their mobility states at several different time points of the next frame based on the AR - 1 mobility estimation model. Each node in the network requires future mobility state information of all the current and potential two-hop neighbor nodes. Using the mobility adaptive algorithm, individual nodes could independently calculate frame times different from each other; leading to synchronization problems in the schedule-based MMAC protocol. The average of these location estimations is regarded as a node's location prediction for the next frame. This information is transmitted to the node's corresponding cluster head. The cluster head is able to collect the values of all its members and broadcasts them in the last slot of a frame. This ensures that all the nodes in the cluster have the best knowledge of the predicted mobility states of its current and potential two-hop neighbors. The responsibility of cluster head is rotated among the nodes of the cluster. So, energy of each and every node in the cluster will retain at an accepted level. After position estimation, node independently proposes new frame duration and transmits it to the cluster head. The cluster head makes an average of the duration estimations from all nodes and produces the mean frame size. After completion of mean frame size cluster head broadcasts it to all the nodes. If this value is less than the previously stored value at a node, it increases the random access interval and decreases the scheduled access interval by keeping the frame time constant. The frame time, however, can only be changed at the end of a round by employing Global Synchronization Period (GSP). The GSP averages the predicated frame durations from all the cluster heads and disseminates this mean value in the network as the frame size for the next round.
\end{abstract}

\subsection{MS-MAC}

MS-MAC is an extension of contention based protocol SMAC to support the mobility of nodes in the, mobile environment [18].

The SMAC protocol works well in the static network, in which the topology change, node joining and node failure are not frequent. In it sync packets are required to update nodes schedule tables to avoid the collision. If a mobile node in the cluster wants to set up a new connection with a node in a different cluster, it has to wait for a new synchronization period, to be able to detect the SYNC message from the new node. During this connection setup time, the mobile node is disconnected from the rest of the network. This waiting period of up to 2 minutes could be far too long for some time critical applications.

Each node discovers the presence of mobility within its neighborhood based on the received signal strength of periodic SYNC messages from its neighbors. The level of the change in the received signals is also related to the speed of the mobile node. This information is used to create an active zone around a mobile node when it moves from one cluster to another cluster, so that the mobile node can expedite connection set up with new neighbors before it loses all its neighbors. In the active zone, nodes run the synchronization periods more often, resulting in higher energy consumption, but the time it takes to create new connections is lower. If mobile node is moving in to the other virtual cluster without knowing the schedule of the cluster creates the worst situation for the communication.

As shown in the figure 4 synchronization periods is changes with speed of the mobile nodes.MS-MAC is not well developed and suffers from the same shortcomings of the SMAC protocol

\subsection{MCMAC}

The mobile cluster MAC is Schedule based MAC protocol. It extends the LMAC and GMAC protocol to deal with the cluster mobility means nodes are move in the group [3]. This protocol designing was focused on application like Wireless Body Area Network for the monitoring of patients [3].

In the GMAC protocol TDMA frame is divided into two equal slots. These slots are active and sleep slots to make a node active and sleep respectively. Further, Active slot is divided into transmission slot and listen slot for transmission and listening respectively. In MCMAC protocol active slot is divided into two separate parts, static active slots and mobile cluster slots [3]. Static Active Slots are dynamically occupied by the static nodes in the network for two hope neighborhood nodes transmission. And in the remaining part of the SAS static nodes receives data packets. Transmission slot is guarded by guard band at the front and at the end for the synchronization purpose. As shown in the figure 5 mobile cluster slots are occupied by the nodes in the mobile cluster for the communication in between nodes. Each slot in the MCS is allocated to one node. In multiple mobile cluster communication transmission slot is extended with CSMA slot to avoid the collision for access of communication channel [3]. 


\subsection{MobiSense}

MobiSense having cross layer architecture (MAC layer and routing architecture) supports the Reliable mobile sensing with low-latency communication and handoffs in micro mobility environment [16]. MobiSense uses discovery slot in common control channel in each and every super- frame to avoid overhearing to save the power of node. As well as beacon messages allows to gather the information of network like traffic load on the channel and access of the channel to initiate handover of the packets with minimum synchronization overhead with cluster head, this reduces the power consumption and the delay. The MobiSense architecture is a hybrid architecture that combines the infrastructure and infrastructure less network [16].

MobiSense provides the distributed and dynamic on-demand transmission scheduling for the better synchronization. This mechanism forms the super-frame into admission mini-slots, uplink and downlink-data transmission slots, and discovery slots. Discovery slots eliminate active and passive scanning on unused channels, while the admission mini-slots allow rapid network convergence and low hand-over latency. In such architecture static infrastructure nodes act as a cluster heads and mobile nodes moves in between clusters like in a cellular network [16]. After segmentation of the network by deciding the clusters, cluster heads dynamically schedules the local communication to get the high throughput requirement with contrast to traffic demands of mobile nodes and low latency over the handover period.

As shown in the figure 6 to gather the rapid network information, during the network discovery slots each cluster heads broadcasts small discrete messages on common channel. And mobile nodes wake-up on the same channel to listen those probes and avoid ideal overhearing. This probes provides the information about cluster size and access of channels, these are helpful for the mobile node to handover from one cluster to another. Due to fixed size of the discovery slots, nodes only listen for fixed duration. After gathering the information, mobile node selects the access mini slot to sends the cluster joining request. This reduces the collision probability [16]. While uplink and downlink data transmission slots are for the two way communication [16].

\subsection{M_TDMA}

M_TDMA is TDMA based protocol with mobility awareness in mobile sensor network [17]. Compared to a pure TDMA, M TDMA partitions the network into non-overlapping clusters using the FLOC algorithm. Each cluster having its own cluster head. Protocol can support intercluster as well intracluster mobility. For mobility pattern intermobility and intramobility model is considered [17]. Most widely Random Walk mobility model is preferred. A slight enhancement of this model is the Random Waypoint model in which pauses are introduced between changes of direction and speed which doesn't reflect the real scenario. Here TDMA based MAC protocol is used to divide the time duration into sequence of slots. These slot assignment is done through TDMA frame structure. Individual slot is assigned to individual node only. In that slot messages are transmitted by that node only and such arrangement should be précised to avoid collision.

Here, timeline is breakdown into sequence of rounds and each is divided into equal number of slots. For joining of the cluster each node (due to mobility of node entrance of node in to the new cluster) should have knowledge of round, frequency and slot for transmission [17].

As shown in the figure 7 TDMA frame schedule is broken down into parts, Control part for the transmission of control information to manage the mobility and transmission while Data part for data transmission. As shown in the fig. 5.7 first three slots are control slots. In the first slot it carries cluster information transmitted by the cluster head. Second slot carries the information about presence of new nodes in the cluster transmitted to the cluster head. In the third slot cluster head broadcasts a new node's slot information. While data slots are assigned or unassigned.

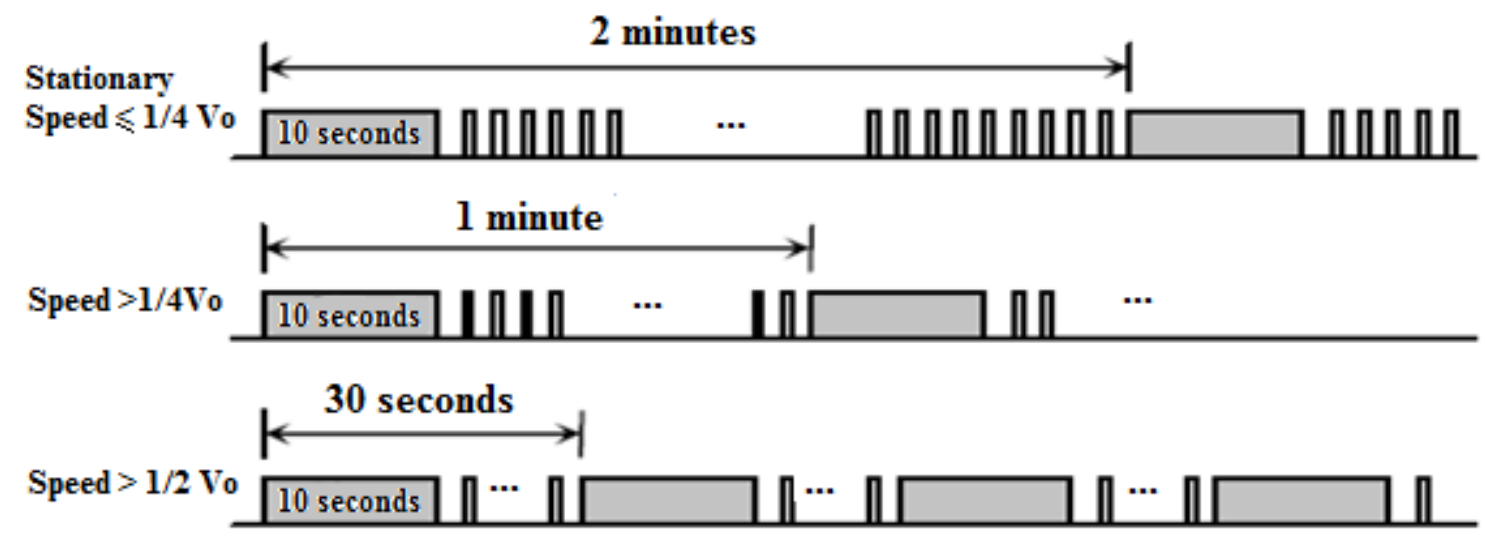

Speed $>V_{0}$

Fig 4: Change in synchronization period with respect to speed of mobile nodes in MS-MAC Protocol [18] 


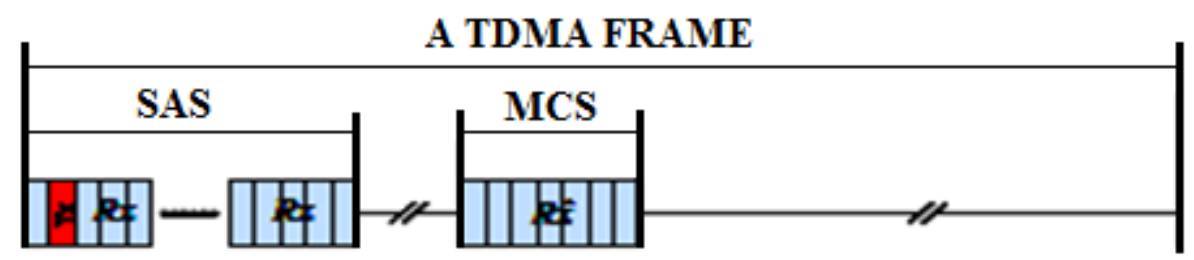

(a)

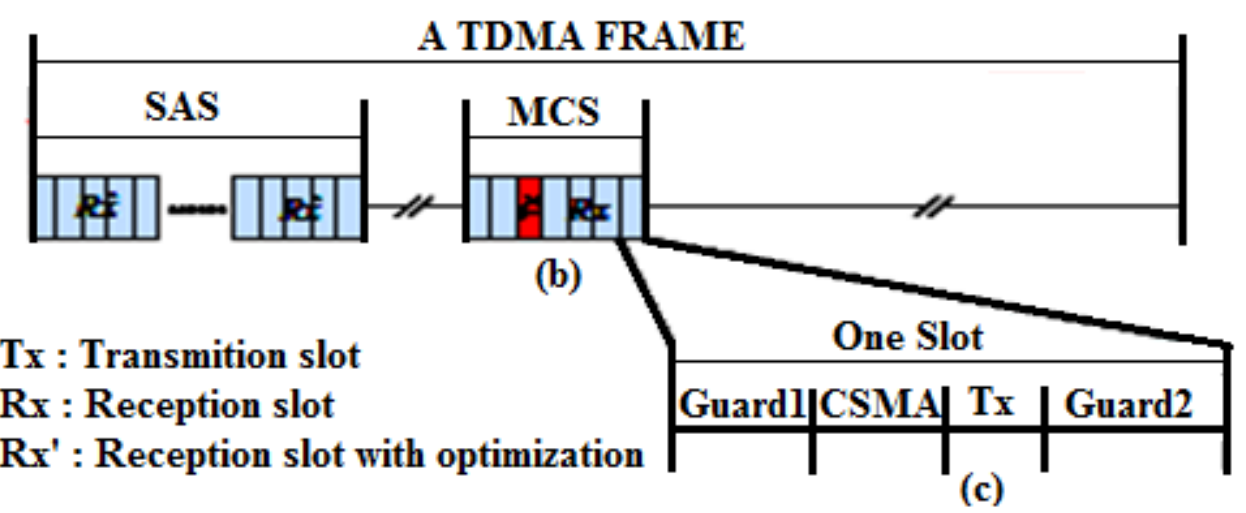

Fig 5: Frame Structure of the MCMAC Protocol [3]

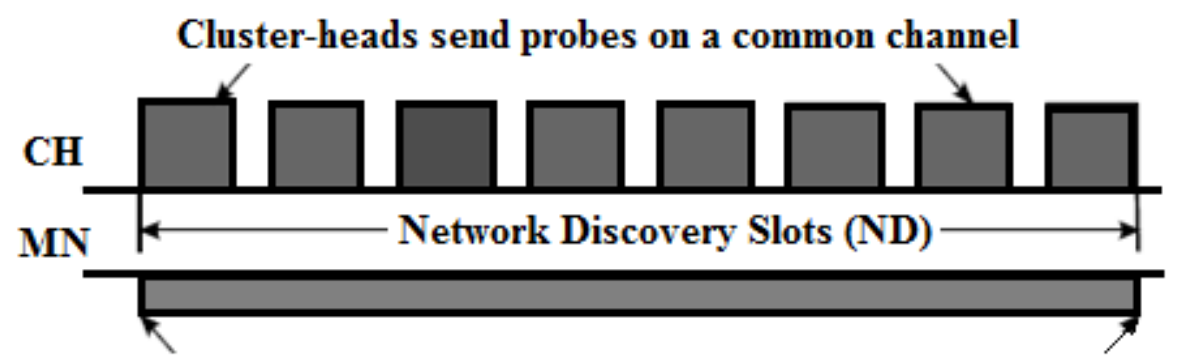

Mobile nodes wake-up on the same channel to listen to those probes, which prevwnts overhearing, while discovery delay is constant

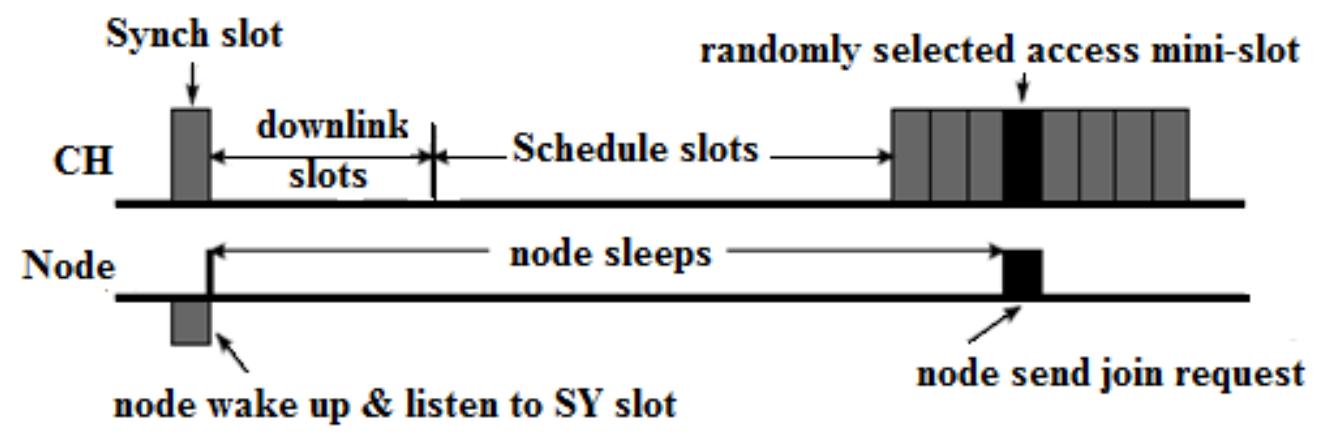

CH - Cluster Head MN - Mobile Node

Fig 6: Super-frame structure of Mobisense Protocol [16] 


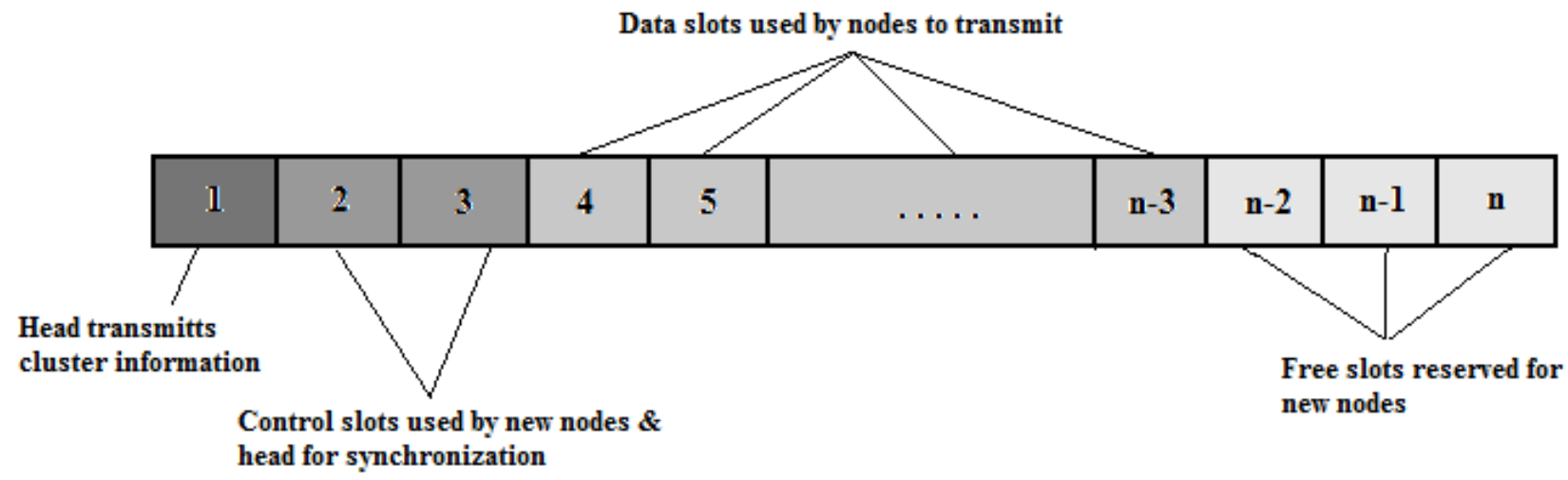

Fig 7: M_TDMA frame structure and Working Mechanism [17]

\section{COMPARISION OF MOBILITY AWRAE MAC PROTOCOLS}

In wireless sensor networks nodes may fail due to hardware failure or battery exhaustion and new nodes may join the network. The network topology is affected by joining or failure of nodes. This regular network topology changes can be considered as a weak mobility. More than one nodes may synchronal fail or join the network. Such synchronal node joins and failures are more difficult to handle, by the MAC protocol. Further, the sensor nodes may physically move from their location can be considered as a Pedestrian mobility pattern or Vehicular mobility pattern or Dynamic medium mobility pattern. Synchronal node joins/failures and physical mobility of nodes considered as a strong mobility [11].

In this paper, we show that the different mobility aware MAC protocols for wireless sensor networks are best suited for, different mobile sensor network environments for different applications. Here we have made comparative analysis of mobility adaptive MAC protocols on the basic attributes like cluster based protocol or not?, TDMA based or CSMA based?, effect of mobility on different parameters like latency, power consumption, synchronization, etc. Comparison of MAC protocols makes very clear about usage of protocol in any application with mobile environment with specific needs. For example, MCMAC protocol is better suited for application like Wireless Body area network to measure different biological parameters of moving patient (mobile nodes) and report them to doctor (sink node) [3] or MobiSense protocol is better suited for the mobile environment facing micro mobility of nodes [16].

Table 1.

Comparative Analysis of Proposed Mobility Aware MAC Protocols

\begin{tabular}{|c|c|c|c|c|c|c|}
\hline Attribute & MA-MAC & M-MAC & MS-MAC & МСМАС & MobiSense & M_TDMA \\
\hline $\begin{array}{l}\text { Schedule based / Contention } \\
\text { based Protocol }\end{array}$ & $\begin{array}{c}\text { Contention } \\
\text { based } \\
\text { protocol. }\end{array}$ & $\begin{array}{l}\text { Schedule } \\
\text { based } \\
\text { protocol. }\end{array}$ & $\begin{array}{l}\text { Contention } \\
\text { based } \\
\text { protocol. }\end{array}$ & $\begin{array}{c}\text { Schedule \& } \\
\text { Contention } \\
\text { based } \\
\text { hybrid } \\
\text { protocol. }\end{array}$ & $\begin{array}{l}\text { Schedule } \\
\text { based } \\
\text { protocol. }\end{array}$ & $\begin{array}{l}\text { Schedule } \\
\text { based } \\
\text { protocol. }\end{array}$ \\
\hline Mobility estimation /detection & $\begin{array}{c}\text { Based on } \\
\text { RSSI } \\
\text { measuremen } \\
\text { t of received } \\
\text { ACK } \\
\text { packets. }\end{array}$ & $\begin{array}{l}\text { Based on the } \\
\text { previous } \\
\text { traffic } \\
\text { information } \\
\text { and location } \\
\text { information } \\
\text { of nodes. }\end{array}$ & $\begin{array}{l}\text { Based on } \\
\text { received } \\
\text { signal } \\
\text { strength of } \\
\text { periodical } \\
\text { synch } \\
\text { messages fro, } \\
\text { neighbor } \\
\text { nodes. }\end{array}$ & $\begin{array}{c}\text { By } \\
\text { measuring } \\
\text { Phase } \\
\text { difference } \\
\text { with } \\
\text { respect to } \\
\text { neighborin } \\
\text { g node. }\end{array}$ & $\begin{array}{c}\text { By } \\
\text { continuously } \\
\text { probing the } \\
\text { environment } \\
\text { by static } \\
\text { cluster head. }\end{array}$ & $\begin{array}{c}\text { By } \\
\text { continuously } \\
\text { probing the } \\
\text { environment } \\
\text { by mobile } \\
\text { node itself. }\end{array}$ \\
\hline Type of mobility detection & $\begin{array}{c}\text { Pedestrian } \\
\text { mobility } \\
\text { (Fast \& } \\
\text { Slow). }\end{array}$ & $\begin{array}{l}\text { Weak and } \\
\text { Strong } \\
\text { Mobility } \\
\text { detection. }\end{array}$ & $\begin{array}{l}\text { Weak and } \\
\text { Strong } \\
\text { Mobility } \\
\text { detection. }\end{array}$ & $\begin{array}{c}\text { Group } \\
\text { mobility } \\
\text { (Mobility } \\
\text { of Cluster). }\end{array}$ & $\begin{array}{l}\text { Micro } \\
\text { mobility. }\end{array}$ & $\begin{array}{c}\text { Intra and Inter } \\
\text { Cluster } \\
\text { mobility. }\end{array}$ \\
\hline MAC protocol extension & $\begin{array}{c}\text { Extension of } \\
\text { XMAC } \\
\text { Protocol. }\end{array}$ & $\begin{array}{c}\text { Extension of } \\
\text { TRAMA } \\
\text { Protocol. }\end{array}$ & $\begin{array}{c}\text { Extension of } \\
\text { SMAC } \\
\text { Protocol. }\end{array}$ & $\begin{array}{l}\text { Extension } \\
\text { of LMAC } \\
\& \text { GMAC } \\
\text { Protocol. }\end{array}$ & $\begin{array}{c}\text { Extension of } \\
\text { TDMA } \\
\text { Protocol. }\end{array}$ & $\begin{array}{c}\text { Extension of } \\
\text { TDMA } \\
\text { Protocol. }\end{array}$ \\
\hline
\end{tabular}




\begin{tabular}{|c|c|c|c|c|c|c|}
\hline $\begin{array}{l}\text { TDMA based / CSMA based } \\
\text { Protocol }\end{array}$ & $\begin{array}{c}\text { CSMA } \\
\text { based } \\
\text { Protocol. }\end{array}$ & $\begin{array}{c}\text { TDMA } \\
\text { based } \\
\text { Protocol. }\end{array}$ & $\begin{array}{l}\text { CSMA based } \\
\text { Protocol. }\end{array}$ & $\begin{array}{c}\text { TDMA } \\
\text { based } \\
\text { Protocol. }\end{array}$ & $\begin{array}{l}\text { TDMA based } \\
\text { Protocol. }\end{array}$ & $\begin{array}{l}\text { TDMA based } \\
\text { Protocol. }\end{array}$ \\
\hline Mobility model & $\begin{array}{l}\text { Pattern } \\
\text { Matching } \\
\text { Model. }\end{array}$ & $\begin{array}{c}\text { Auto } \\
\text { Regression } \\
\text { Model (AR- } \\
\text { 1). }\end{array}$ & $\begin{array}{c}\text { Information } \\
\text { Theoretic } \\
\text { Model. }\end{array}$ & $\begin{array}{c}\text { Reference } \\
\text { Point } \\
\text { Group } \\
\text { Mobility } \\
\text { Model and } \\
\text { Random } \\
\text { Waypoint } \\
\text { Model. }\end{array}$ & $\begin{array}{l}\text { Information } \\
\text { Theoretic } \\
\text { Model. }\end{array}$ & $\begin{array}{c}\text { Inter and Intra } \\
\text { Cluster } \\
\text { Mobility } \\
\text { Model. }\end{array}$ \\
\hline Schedule broadcasting & Not needed. & $\begin{array}{c}\text { Done } \\
\text { through } \\
\text { cluster head. }\end{array}$ & $\begin{array}{l}\text { Done through } \\
\text { cluster head. }\end{array}$ & $\begin{array}{l}\text { Done } \\
\text { through } \\
\text { cluster } \\
\text { head. }\end{array}$ & $\begin{array}{l}\text { Done through } \\
\text { cluster head } \\
\text { and sink } \\
\text { nodes. }\end{array}$ & $\begin{array}{l}\text { Done through } \\
\text { cluster head } \\
\text { in cluster. }\end{array}$ \\
\hline $\begin{array}{l}\text { Supports Inter / Intra Cluster } \\
\text { mobility }\end{array}$ & $\begin{array}{l}\text { Can support } \\
\text { both. }\end{array}$ & $\begin{array}{l}\text { Can support } \\
\text { both. }\end{array}$ & $\begin{array}{c}\text { Can support } \\
\text { Intra Cluster } \\
\text { Mobility.. }\end{array}$ & $\begin{array}{c}\text { Can } \\
\text { support } \\
\text { both. }\end{array}$ & $\begin{array}{c}\text { Can support } \\
\text { Intra Cluster } \\
\text { Mobility. }\end{array}$ & $\begin{array}{l}\text { Can support } \\
\text { both. }\end{array}$ \\
\hline $\begin{array}{l}\text { Effect on synchronization with } \\
\text { respect to speed of mobility }\end{array}$ & Can't effect. & Can effect. & Can effect. & $\begin{array}{l}\text { Cants } \\
\text { effect. }\end{array}$ & Can effect. & Can't effect. \\
\hline Data packet Handover initiation & $\begin{array}{l}\text { Can be done } \\
\text { from } \\
\text { Transmitter } \\
\text { side. }\end{array}$ & NA & $\begin{array}{l}\text { Can be done } \\
\text { through } \\
\text { mobile node } \\
\text { itself. }\end{array}$ & NA & $\begin{array}{l}\text { Can be done } \\
\text { through } \\
\text { mobile node } \\
\text { itself. }\end{array}$ & NA \\
\hline Effect of mobility on the Latency & $\begin{array}{c}\text { Provides } \\
\text { high latency } \\
\text { during low } \\
\text { mobility of } \\
\text { nodes. }\end{array}$ & $\begin{array}{l}\text { Provides } \\
\text { Latency due } \\
\text { to random } \\
\text { access while } \\
\text { overcome } \\
\text { the mobility } \\
\text { of nodes. }\end{array}$ & $\begin{array}{l}\text { Mobility } \\
\text { doesn't affect } \\
\text { the latency } \\
\text { but also don't } \\
\text { increase. }\end{array}$ & $\begin{array}{c}\text { Provides } \\
\text { low } \\
\text { Handoff } \\
\text { Latency. }\end{array}$ & $\begin{array}{c}\text { Provides low } \\
\text { latency during } \\
\text { handoff. }\end{array}$ & $\begin{array}{l}\text { Increased } \\
\text { latency. }\end{array}$ \\
\hline Scheduling (Dynamic / Static). & N.A. & $\begin{array}{c}\text { Dynamic } \\
\text { Scheduling. }\end{array}$ & $\begin{array}{l}\text { Static and } \\
\text { Dynamic } \\
\text { Scheduling. }\end{array}$ & $\begin{array}{c}\text { Static as } \\
\text { well } \\
\text { Dynamic } \\
\text { Scheduling. }\end{array}$ & $\begin{array}{l}\text { Dynamic } \\
\text { Scheduling. }\end{array}$ & $\begin{array}{c}\text { Static as well } \\
\text { Dynamic } \\
\text { Scheduling. }\end{array}$ \\
\hline $\begin{array}{c}\text { Prediction of Future Mobility } \\
\text { Pattern }\end{array}$ & Can't detect. & Can detect. & Can't detect. & Can detect. & $\begin{array}{l}\text { Can detect } \\
\text { with some } \\
\text { limitations. }\end{array}$ & Can't detect. \\
\hline $\begin{array}{c}\text { Detection of Direction and Speed } \\
\text { of Mobile Node }\end{array}$ & $\begin{array}{l}\text { Can detect } \\
\text { speed of } \\
\text { mobile not } \\
\text { direction. }\end{array}$ & $\begin{array}{l}\text { Can detect } \\
\text { through auto } \\
\text { regressive } \\
\text { algorithm. }\end{array}$ & $\begin{array}{l}\text { Can detect } \\
\text { speed of } \\
\text { mobile. }\end{array}$ & $\begin{array}{l}\text { Can detect } \\
\text { using } \\
\text { Random } \\
\text { Waypoint } \\
\text { Mobility } \\
\text { Model. }\end{array}$ & Can't detect & $\begin{array}{c}\text { Can detect } \\
\text { using } \\
\text { extension of } \\
\text { Random } \\
\text { Waypoint } \\
\text { Mobility } \\
\text { model. }\end{array}$ \\
\hline Advantage & $\begin{array}{l}\text { It can handle } \\
\text { mobility in } \\
\text { time. }\end{array}$ & $\begin{array}{c}\text { Time slots } \\
\text { can allocate } \\
\text { dynamically } \\
\text { for mobile } \\
\text { nodes. }\end{array}$ & $\begin{array}{l}\text { The } \\
\text { synchronizati } \\
\text { on frequency } \\
\text { can adapt to } \\
\text { the speed of a } \\
\text { mobile node's } \\
\text { Neighbors. }\end{array}$ & $\begin{array}{l}\text { Dynamic } \\
\text { occupation } \\
\text { of active } \\
\text { static slots. }\end{array}$ & $\begin{array}{l}\text { The mini- } \\
\text { slots ensure } \\
\text { rapid } \\
\text { admission } \\
\text { And fast } \\
\text { network } \\
\text { convergence. }\end{array}$ & $\begin{array}{l}\text { Mobility can } \\
\text { be adapted by } \\
\text { control and } \\
\text { data part } \\
\text { without } \\
\text { changing the } \\
\text { size of frame. }\end{array}$ \\
\hline Power Consumption & $\begin{array}{l}\text { Consumes } \\
\text { less power } \\
\text { by avoiding }\end{array}$ & $\begin{array}{l}\text { Consumes } \\
\text { less power } \\
\text { on average }\end{array}$ & $\begin{array}{l}\text { High power } \\
\text { consumption } \\
\text { due to }\end{array}$ & $\begin{array}{c}\text { Power } \\
\text { consumptio } \\
\text { n decreases }\end{array}$ & $\begin{array}{l}\text { Consumes } \\
\text { less power } \\
\text { over a high }\end{array}$ & $\begin{array}{c}\text { Power } \\
\text { consumption }\end{array}$ \\
\hline
\end{tabular}




\begin{tabular}{|c|c|c|c|c|c|c|}
\hline & $\begin{array}{c}\text { retransmissi } \\
\text { on compared } \\
\text { to XMAC. }\end{array}$ & $\begin{array}{l}\text { compared to } \\
\text { TRAMA by } \\
\text { avoiding } \\
\text { retransmissi } \\
\text { on. }\end{array}$ & $\begin{array}{l}\text { creation of } \\
\text { active zone } \\
\text { around the } \\
\text { mobile node. }\end{array}$ & up to $70 \%$. & $\begin{array}{l}\text { data rate } \\
\text { scenario. }\end{array}$ & increased. \\
\hline Application & $\begin{array}{l}\text { Suitable for } \\
\text { healthcare } \\
\text { application } \\
\text { like, to } \\
\text { monitor } \\
\text { movements } \\
\text { of medical } \\
\text { staff or } \\
\text { activities of } \\
\text { patients. }\end{array}$ & $\begin{array}{l}\text { Suitable for } \\
\text { sensor } \\
\text { networks } \\
\text { with high } \\
\text { network } \\
\text { dynamics or } \\
\text { mobile } \\
\text { nodes. }\end{array}$ & $\begin{array}{l}\text { Suitable for } \\
\text { disaster } \\
\text { management } \\
\text { application } \\
\text { and for } \\
\text { military } \\
\text { application. }\end{array}$ & $\begin{array}{l}\text { Medical } \\
\text { Application } \\
\text { s (To } \\
\text { monitor } \\
\text { specific } \\
\text { biological } \\
\text { parameter s } \\
\text { of moving } \\
\text { patient) }\end{array}$ & $\begin{array}{l}\text { Suitable to } \\
\text { monitor the } \\
\text { activity of } \\
\text { hurdle of } \\
\text { animals in } \\
\text { restricted area } \\
\text { and In } \\
\text { Industrial } \\
\text { Automation }\end{array}$ & $\begin{array}{c}\text { Suitable for } \\
\text { any mobile } \\
\text { wireless } \\
\text { sensor } \\
\text { network } \\
\text { application } \\
\text { with limited } \\
\text { mobile nodes. }\end{array}$ \\
\hline
\end{tabular}

\section{CONCLUSION}

After detailed and comparative analysis of Mobility Aware MAC protocols in mobile wireless sensor network application, it can be concluded that mobility aware mac protocol like MCMAC protocol is better suited in medical application for continuous/periodic measurement of the moving patient's biological parameters in hospital, because power consumption is decreased up to $70 \%$ using MCMAC protocol compared to LMAC and GMAC protocols. Considering another case like continuous monitoring of moving object in military application, MAMAC can perform better than the MS-MAC, because MAMAC implementation doesn't need to create active zone around the mobile node and avoid retransmission, these reduces the power consumption. So, different mobility aware mac protocol is better than other mobility aware mac protocol with respect to requirements of mobile wireless sensor network application like less power consumption or less transmission delay or high network throughput.

\section{ACKNOWLEDGMENTS}

I thank, Asst. Prof. A. A. Bavarva, School of Engineering, R.K University, Rajkot, Gujarat, India for his valuable guidance, constant encouragements, over willing help and sustained interest right from the selection of my topic up to the final shaping.

\section{REFERENCES}

[1] Survey P. Huang, L. Xiao, S. Soltan, M. W. Mutka, and N. Xi, "The Evolution of MAC Protocols in Wireless Sensor Networks: A Survey", IEEE Communications Surveys \& Tutorials, Vol. 15, No. 1, First Quarter 2013.

[2] W. Dargie, "A medium access control protocol that supports a seamless handover in wireless sensor network", Journal of Network and Computer Applications 35 (2012) 778 - 786.

[3] M. Nabi, M. Blagojevic, M. Geilen, T. Basten, and T. Hendriks, "MCMAC: An optimized medium access control protocol for mobile clusters in wireless sensor networks," 7th Annual IEEE Communications Society Conference on Sensor Mesh and Ad Hoc Communications and Networks (SECON), pp. 1-9, June 2010.

[4] P. Wang and I. F. Akyildiz," Effects of Different Mobility Models on Traffic Patterns in Wireless Sensor
Networks", IEEE COMMUNICATION \& TUTORIALS, 2010.

[5] M. Srbinovska, V. Dimcev, C. Gavrovski and Z. Kokolanski, "Localization Techniques in Wireless Sensor Networks using Measurement of Received Signal Strength Indicator" Electronics, Vol. 15, No. 1, June 2011.

[6] H. Karl and A. Willig, "Protocols and Architectures for Wireless Sensor Networks", John Wiley \& Sons, 2005.

[7] P. Ji, C. Wu, Y. Zhang, Z. Jia ,'Research of an Energy aware MAC protocol in Wireless Sensor Network", 2008 Chinese Control and Decision Conference ( CCDC 2008),IEEE 2008, pp. 4686-4690.

[8] W. Ye, J. Heidemann, and D. Estrin, "An energyefficient mac protocol for wireless sensor networks," in Proc. IEEE INFOCOM, New York, NY, June 2002, pp. $1567-1576$.

[9] Z. R. Zaidi and B. L. Mark, "Mobility Estimation for Wireless Networks Based on an Autoregressive Model", IEEE Communications Society, Globecom 2004, pp. 3405-3409.

[10] Papa Dame Ba · Ibrahima Niang · Bamba Gueye "An optimized and power savings protocol for mobility energy-aware in wireless sensor networks", Springer Science+Business Media New York 2013.

[11] M. Ali, T. Suleman, and Z. A. Uzmi, "MMAC: A Mobility- Adaptive, Collision-Free MAC Protocol for Wireless Sensor Networks", IEEE 2005, pp. 401-407.

[12] M. Buettner, G. V. Yee, E. Anderson, R. Han,"X-MAC: A Short Preamble MAC Protocol for Duty-Cycled Wireless Sensor Networks", SenSys'06, November 1-3, 2006, Boulder, Colorado, USA.

[13] A. El-Hoiydi and J.-D. Decotignie "WiseMAC: An Ultra Low Power MAC Protocol for the Downlink of Infrastructure Wireless Sensor Networks", 2004 IEEE, ISCC'04, pages 244-251, Alexandria, Egypt, June 2004.

[14] C. Schindelhauer, "Mobility in Wireless Networks", J. Wiedermann et al. (Eds.): SOFSEM 2006, LNCS 3831, pp. 100-116, Springer-Verlag Berlin Heidelberg, 2006.

[15] Z. Tang and W. Dargie, "A mobility-aware medium access control protocol for wireless sensor networks", The fifth IEEE international workshop on 
Heterogeneous, Multi-Hop, Wireless and Mobile Networks (Globecom 2010), December 2010.

[16] A. Gonga, O. Landsiedel, and M. Johansson, "MobiSense: Power efficient micro-mobility in wireless sensor networks," Proc. 7th IEEE International Conference on Distributed Computing in Sensor Systems, June 2011.

[17] A. Jhumka and S. Kulkarni, "On the design of mobilitytolerant tdma based media access control (mac) protocol for mobile sensor networks," Proc. 4th international conference on Distributed computing and internet technology, vol. 4882, pp. 42-53, 2007.

[18] H. Pham and S. Jha, "An adaptive mobility-aware mac protocol for sensor networks (ms-mac)," IEEE International Conference on Mobile Ad-hoc and Sensor Systems, pp. 558 - 560, October 2004. 